\title{
Community as a Sustaining Force: Strategies for Online Scholarly Support
}

Bonnie Mullinix, EdD

Walden University, Minneapolis, Minnesota, United States

(iD https://orcid.org/o000-0002-3816-7100

Alison Binger, $\mathrm{PhD}$

University of the People, Pasadena, California, United States

iD https://orcid.org/o0oo-0002-1151-7027

Michael Lees, $\mathrm{PhD}$

Montclair State University, Montclair, New Jersey, United States, (iD https://orcid.org/oooo-0001-8044-8662

Contact: bonnie.mullinix@waldenu.edu

\section{Abstract}

This paper discusses the ways that community connections serve to sustain and support scholarly growth, retention, and success, particularly in longer-term online contexts. These strategies are seen through the reflective experience of a faculty mentor and two recent graduates who co-developed community support strategies that help doctoral students stay motivated, connected, and succeed over many years of what might otherwise be a long, individual, and lonely journey-particularly when undertaken online. A matrix of strategies, apps, and online tools emerged from this process and is offered for consideration.

Keywords: distance education, community support strategies, sustainability for online student success

Date Submitted: March 18, 2021 | Date Published: October 21, 2021

Recommended Citation

Mullinix, B., Binger, A., \& Lees, M. (2021). Community as a sustaining force: Strategies for online scholarly support. Journal of Educational Research and Practice, 11, 249-258. https://doi.org/10.5590/JERAP.2021.11.1.18

\section{Introduction}

While academic scholarship often needs individual focus to flourish, it can also be a lonely and isolating experience, causing emergent scholar-learners to question whether they should continue their journey. Isolation can be particularly problematic in online environments and, when steps are not taken to counteract, can form a barrier that keeps students from feeling connected through sharing ideas and best practices, which often results in missed opportunities for fostering personal, professional, and educational development (Kotera et al., 2020; Stevenson \& Bauer, 2014). There has long been attention to identifying effective practices in higher education and considering how to apply such practices utilizing emergent technologies (Chickering \& Ehrmann, 1996; Kaufmann \& Vallade, 2020). Yet, issues related to building and maintaining connections persist and require constant vigilance. Building community in an online environment serves as an overarching 
strategy that helps students feel connected and increases the likelihood of their success (Wehler, 2018; Zhang et al., 2020). Community connections have been found to sustain and support scholarly growth, retention, and success (Bawa, 2016; Erickson \& Neset, 2014; Palloff \& Pratt, 1999).

This paper explores key elements of building long-term online communities and engaging students by identifying strategies for sustaining connections and community. These strategies are drawn from the casebased experience and the evolution of a community built by students of disparate interests and backgrounds (at various stages in their studies) who are situated across multiple time zones. This paper collects and shares participant reaction to the process and its impact on their learning experience. Early participants had a particular influence on shaping the community and contributing to the identification, design, and development of interactions and activities. This paper highlights the experiences of two early participants who reflect on how they helped develop and facilitate regular online synchronous meetings, co-created an effective learning agreement format/template, and shared experiences coordinating and collaborating on presentations. Their descriptions of experiences (over $3-5$ years of study) illustrate how the flow and interconnection between these experiences qualify as successful and sustaining strategies.

\section{Case Context: Community Building in a Long-Term Online Doctoral Studies Program With a Taste of Hybrid Residencies}

As the case context is central to this discussion, sharing it early on is appropriate. While term-based online courses require community and connection, the opportunities to integrate community are confined to 15 weeks, 11-12 weeks, or even 7.5 weeks or less, and are limited by their relatively short duration. The ability to determine whether or not these efforts actually sustain students in their studies is increased with contexts that are focused on longer-term programs of study, such as doctoral degree programs. This case is situated within an international online university's $\mathrm{PhD}$ in Education program.

Doctoral candidates are assigned a mentor and/or chair after coursework as they begin their dissertation journey. They are then invited into a Research Forum community within the Learning Management System (LMS). Here they join a community of colleagues on a similar journey that takes a minimum of 2-3 years. This context allows plenty of time to explore how to build a community and consider which elements contribute to sustaining students through their longer-term scholarly studies.

In this case, early members of this Research Forum worked with their mentor to explicitly explore elements of the community and ways to strengthen it. These strategies included the following online components:

1. fostering personal connection;

2. clear expectations and timely communications;

3. focused discussions;

4. monthly synchronous meetings;

5. shared facilitation responsibilities;

6. structured individual learning agreements;

7. collaborative projects; as well as

8. periodic multi-day face-to-face residencies.

Some of these elements were embedded in the design of the LMS-Based Research Forum "course" and/or doctoral requirements, while others were initiated by the mentor in collaboration with the early mentee/doctoral candidates (two of whom are co-authors of this paper). All are worthy of considering as elements that sustain community. 


\section{Key Elements Needed to Build and Sustain Long-Term Online Communities}

Understanding key elements that build community, foster interaction, and support connection in an online educational environment is essential for distance learning success. There is little doubt that community fosters a sense of belonging for students, which in turn motivates participation and interaction (Gares et al., 2020; Shea, 2004). Muirhead (2007) offered six strategies that positively impact student motivation and engagement. They include: (a) challenging students to think beyond their knowledge and skills; (b) studentcentered freedom to complete instructor defined goals; (c) resources that include the integration of online relationships and community building; (d) work-group features that personalize online classroom relationships; (e) supervisory encouragement in which the teacher/mentor serves as a guide in assisting students through difficult moments; and (f) organizational support on the part of the larger institution in which the online classes are housed so teachers and students feel their efforts are respected and valued (Muirhead, 2007, p. 4).

These observations and those of other researchers align well with the elements built into our context and casespecific experience, and were found to be effective in sustaining emergent scholars. The following identifies each element in general, connects it to other observations and research in the field, and ends with a quote from the co-authors who, as students, experienced and/or co-created each observation. Taken together, these observations begin to illustrate the power that community connections offer as a sustaining force.

\section{Fostering Personal Connection}

Early individualized connection through the "Mentee's café" allows for faculty-student/mentor-mentee connections and student-student connections that begin to build trust, share experiences, and look for commonalities to connect individuals to each other. Researcher-practitioners (Stone, 2016; Wehler, 2018) confirm that online classrooms require deliberate efforts to create such interaction, to ensure that these are meaningful and relevant to both of the parties participating. While this initial connection begins the process, it is continued through discussions, video-based meetings, mentor-mentee phone calls, and more. Actively engaging in online interactions requires that students feel welcome, safe, acknowledged and connected.

The feeling of having a true mentor, one that will motivate me, guide me, be stern when needed, and then reassure me that I can do this, was absolutely essential in feeling connected to the process and broader scholarly community. It was having conversations outside of our classroom, learning about her personal life and family, and the feeling of compassion and empathy between us that really provided me with the support needed to get through the program. - Alison

\section{Clear Expectations}

Course structure, participation expectations, regular announcements and communications, and modeling and monitoring to ensure proper netiquette are regular parts of our Research Forum practice. Providing structure, rules, and guidelines for acceptable behavior are common characteristics of online community communications that help to ensure community members respect differences in culture and ensure that any inappropriate interactions are addressed (Shea, 2004). Encouraging interaction while ensuring individuals employ netiquette helps all students feel safe in the online classroom, and structure helps to make the path forward clear.

The online classroom encouraged interaction through regular, structured, and academic discussions. The professor modeled high expectations and standards of scholarly conduct, respectful behavior, and ensured a safe arena to discuss cultural and educational topics. There were students from multiple areas of the country, as well as outside of the United States, from many cultures, religions, and political affiliations. Our professor and the class as a whole would help each other understand the many viewpoints we had. There were times that I adjusted wording in my 
presentations, and I continuously ensured I used appropriate multicultural etiquette when discussing topics. It was absolutely wonderful to be able to understand different viewpoints and to be able to talk about them in a safe, caring, and scholarly environment. Our discussions were always productive, and we all were eager to meet again. - Alison

\section{Structured Learning Agreements and Individualized Planning}

Our case setting uses individualized learning agreements in the form of term plans that require clear goals and weekly plans to meet those goals that guide mentee work and facilitate mentor monitoring and check ins. Term plans are approved and followed up with progress report(s), the possibility for amendment, and final reporting. These together with completed submissions, as planned, justify a satisfactory end-of-term grade.

Other documents, required along the way, also guide individualized research designs and work plans. Motivation is an essential aspect of promoting creativity and creative processes as it concerns critical thinking, problem solving, and the fostering of new ideas. These elements of creativity are the foundation of healthy student academic outcomes and educational experiences and providing structure to facilitate planning (Muirhead, 2007).

I felt that the use of structured learning agreements and individualized planning as a requirement for course completion was very helpful. I have very fond memories of working on this with my mentor/dissertation chair as we embarked on a quest to develop plan outlines, which adequately addressed work needed for completion and milestones-particularly as it related to how students filled out the learning agreements and quarter plans. Use of these tools established a framework for completing current coursework, setting individual parameters for getting work done, while also considering future projections. They also helped tremendously in developing a relationship between my mentor/dissertation chair and myself. - Michael

\section{Focused Topic/Skills Oriented Discussions}

In longer-term communities, where individual work is the focus, Research Forum discussions need to be relevant, topical, and oriented on developing useful skills and uncovering useful resources. Faculty generally determine frequency and focus of discussions and develop and share discussion prompts that are particularly generative. Discussions also offer the opportunity to engage students in identifying and selecting preferred topics.

The discussions brought together individuals from diverse backgrounds with multiple perspectives ensuring scholarly discourse through topical questions that prompted us to create, problem solve, and theorize. The topics for discussions, as well as our monthly Zoom meetings, typically revolved around cultural education and/or improving scholarly skills. Such discussion experiences began to connect me with fellow students and build my sense of community. - Alison

\section{Monthly Synchronous Meetings}

Synchronous meetings are not a required component of the standard Research Forum, but they are the collective brainchild of our community, and are a centerpiece and lynchpin of our shared experience. What started as a kernel of an idea was grown by our early cohort and evolved from an experimental endeavour to a quarterly gathering and then, after much scheduling and negotiation, into a monthly meeting that coincided with our focused discussions (Introductions, Weeks 5-6, and Weeks 9-10 of an 11-week quarter). Monthly meetings are far and away the activity most often mentioned and appreciated by all.

O'Malley (2017) notes that encouraging discussion through video or video conferences creates an online community in a class where students are not likely to meet each other in person. This type of interaction promotes social presence-a connection on a human and emotional level. Social presence is more likely to 
occur when students move beyond reading and written communications to actually seeing, hearing, and engaging in synchronous dialogue with each other.

We agreed that the typewritten aspect of the research discussion forum helped to further our work. However, we had come to the general consensus that taking the interaction up a few notches might foster more motivation and inspiration while simultaneously deepening a sense of community. We came up with the idea of creating an online meeting for everyone in the research forum that occurred in Skype and Zoom synchronous video formats. The net result helped me tremendously. The opportunity to see, listen, challenge, and support one another in the form of mentor- or studentled first-of-the-month meeting times set the tone for the following weeks. I found myself to be (a) thinking more creatively; (b) motivated towards continuing my work; (c) challenged by the feedback I received; (d) able to work with problem solving based on that feedback; and (e) thinking critically about my work. [M] ost of all, I experienced a sense of community. I realized that I was not alone sitting at my dining room table trying to survive doctoral studies and a dissertation. The sense of community that was built around these face-to-face, online meetings was nothing short of inspirational, as they provided a feeling of being recharged, ready to dive back into my dissertation work, and keep on going. - Michael

\section{Shared Facilitation Responsibilities}

Communities are not created alone, nor are they the responsibility of a single individual. We determined early on that responsibility for identifying and selecting focal topics should be a collective and collaborative undertaking. Participants offered to take responsibility for specific dates associated with an asynchronous discussion and a synchronous meeting. They then identified a topic and worked with the faculty mentor to craft appropriate discussion prompts and were designated as the lead facilitator for both the text-based and live discussions.

Opting to offer students choices in online learning environments provides an opportunity to foster individual and group motivation and creativity. If a strong sense of motivation is fostered, it supports the establishment of wanting to participate, to be a part of, and to extend newfound relationships within a learning community further-during and after online learning occurs (Muirhead, 2007).

Once we started having our monthly face-to-face, online Zoom meetings, students would volunteer to facilitate, choose the topic, present, and lead an hour-long discussion with the group. This would often be the same topic for the text discussion. Whenever there was no volunteer, our professor chose the topic, which generally directed our conversations to ensure scholarly skills development, discourse, and an expansion in our understanding. Both types of focused-topic discussions were important for community building. When our professor lead the discussion topic, we built our community through group learning, which was more traditional with the professor guiding us. When the student lead the discussion topic, our professor stepped back so we could build our community through being the teacher. It was amazing how gently our cohorts guided [us] as we presented. We made mistakes together, laughed together, and cheered each other on. It goes to show the deep bond we created and the great respect we had for each other's thoughts, opinions, and beliefs. - Michael

\section{Collaborative Projects}

Whether collecting and annotating resources or encouraging co-facilitation of topics, we pursued opportunities for facilitating collaboration. We explored and used Google Docs and other online collaboration tools to help form teams, select topics, identify meeting times, and collect and share information. Choice, creativity, and direction were seeded to participants wherever possible. We know and acknowledge that encouraging students to stay motivated requires that attention be paid to individual intrinsic motivation, if student creativity is to develop productively within online learning environments (Muirhead, 2007). Online 
instructors who bring a human-centered approach to the online classroom tend to do the following: (a) initiate interactions inside and outside the classroom, (b) interact in real time, (c) incorporate multimedia and collaborative tools, and (d) make use of learning agreements (O’Malley, 2017; Talbert, 2015; Williams, 2011).

A classroom interaction that I found quite helpful with building scholarly skills was using Google Docs. As a community, we would begin a topic we could each build upon. We would each add our part to the document, building an increasingly complex document that included more information and would have taken much longer to complete if it was a solo activity. It was also incredibly helpful to use Google Apps as I was able to understand the many ways this application could be used for online learning and with any online community spread across the United States or even the world. Using the application during my PhD program prepared me for real-world experiences, such as writing this article with my co-authors. - Alison

\section{Face-to-Face Residencies}

In this case setting, doctoral degrees include a face-to-face component in the form of 3-4 day residencies with immersive and intensive seminars, consultations, and working sessions to help guide individuals through their doctoral studies and dissertation process across key milestones. Residencies have served as an anchoring community experience at this university since its early pre-online distance education years.

Ongoing evaluation of nearly 50 years of residencies confirms that students find residencies to be central to their sense of community, grounding in their doctoral process, and important for offering networking opportunities. While this residency structure and focus may be unique at institutional and program levels, the residency experience is not. The contributions to sense of community, connectivity, and networking potential have long been found in the residency components of otherwise online programs (Rovai \& Jordan, 2004; Vincenzes et al., 2015). While not the traditional interpretation of a hybrid experience, at the program pathway level this periodic residency feature has proven to be powerful and important to maintaining, serving, and sustaining students.

Residencies were essential for me to feel connected to this online educational community. During these 3- to 4-day intensive gatherings, I was able to network and build my confidence in my scholarly abilities, and the intimate groupings and gatherings provided me the opportunity to sit next to, talk to, and meet other students. It was in this environment that I met lifelong friends. Michael

\section{Engaging Students in Co-Creating Community}

Communities must be co-created. While initiation of community should rightly begin with the faculty and be supported by the design of the online course platform, the next step is to actively engage students in contributing to, imagining, and creating the community. Co-creation leads to a sense of ownership and responsibility for the health of the community.

The establishment of community in online learning environments requires maintaining balance amongst the educator, the course construction, and the student-as well as educator willingness to allow the space for student-centered activities to occur (Bawa, 2016; Donovan, 2020; Muirhead, 2007; Shea, 2004; Trespalacios \& Perkins, 2016; Wehler, 2018). Effective student-centered strategies provide the opportunity for students to experience a sense of contribution (while being challenged and supported) and personal ownership in online classrooms.

In our case, two of this paper's co-authors (who are recent $\mathrm{PhD}$ graduates from this university) were central in the development of our community. The third co-author served as their mentor/chair and primary facilitator of this process via the LMS. Both early participants were part of the same program specialization (Global and Comparative Education). As such, their paths were near parallel; they shared a chair, a Research Forum and 
community, and a number of critical activities including residency experiences. While existing structures served to sustain them, as early members of a community of mentees, they also helped co-create many of the community support structures that fostered connections that would sustain them throughout their years of study. The quotes extracted from their reflective narratives highlight the key elements section of the paper above, sharing aspects of their doctoral experience they found to be most sustaining.

\section{Effective Strategies for Building Online Community}

Motivation plays a central role in the development of creativity (Muirhead, 2007), but maintaining student motivation and attention in online learning environments is difficult (Bawa, 2016; Muirhead, 2007; O'Malley, 2017; Stone, 2016). Attention to motivation provides the opportunity to establish online course dynamics that support student willingness to actively engage in, be challenged by, and experience a feeling of connection to coursework and community.

Fostering and maintaining student motivation in an online learning environment presents unique challenges for instructors and students alike, especially as it concerns the development of learning experiences that address creative constructs, retention, educational outcomes, and community building (Bawa, 2016; Muirhead, 2007; O'Malley, 2017; Shea, 2004; Stone, 2016). The promotion of interaction, collaborative learning, socially constructed meaning, resource sharing, support, and encouragement in online learning environments has had a positive influence on the establishment of a sense of community between educator and students (Trespalacios \& Perkins, 2016, p. 38). The positive interactions and collaborations in online meetings created community and motivated doctoral students to continue, stay connected, and complete their programs.

\section{Matrix of Tools for Building and Sustaining Online Community}

The following tools have been found to assist in building and sustaining community in an online learning environment, and they leverage learner choice, engagement, opinions, and dialogue (Mullinix, 2018).

- Gathering Options, Soliciting Preferences, and Availability: Tricider

- Scheduling Meetings (events and invitations): Doodle, Google Calendar, and Outlook Calendar

- Preparation and Preliminary Discussions: Community discussions

- Virtual Meetings (synchronous with video): Zoom, Google Hangouts, and/or Skype

○ Follow-Up: LMS, posting video recordings

- Communications: Email and announcements

○ Personalizing posts-photos, multimedia/videos, etc.

- Student Presentations: Synchronous video meetings, LMS-posted presentations, face-to-face residencies

- Well-Written Student Papers: LMS, shared drives, and mentor/educator websites

For additional detail and a matrix view with links to specific tools, see https://tinyurl.com/DLA19SustainCommunity.

\section{Conclusion}

The community built in the Research Forum was strengthened through the vision and commitment of its earliest participants, the co-authors of this paper. Together they worked with others to co-create and enhance activities to build community in their online environment. For these two students, this community was further solidified through shared residency experiences and culminated in their decision to wait until both had 
completed their dissertations to participate in commencement; where they were third and fourth across the stage (among a field of nearly 500 doctoral candidates) and were hooded by their chair and co-author. Photos and videos of this capstone experience were shared with their long-time colleagues, contributing to the connection and motivation in this robust online community.

While online learning has the danger of being a solitary endeavour, online communities offer a solution. However, community must be co-created. The positive interactions and collaborations in monthly online meetings create a type of community that provided a support network of scholars. This supportive environment inspired and motived these doctoral students, throughout their programs, to persist, connect, and reach their goals.

Valuing and inviting student perspective, regarding the potential and power of various online strategies, is essential to success. Additional strategies involve recognizing the importance of choice, voice, and scholarly dialogue; distributed responsibility; and mentor support strategies that sustain and promote participation. When implemented with care and attention, it is possible to create communities that not only support but also sustain learners throughout their studies and beyond. 


\section{References}

Bawa, P. (2016). Retention in online courses: Exploring issues and solutions-a literature review. SAGE Open, 1-11. https://doi.org/10.1177/2158244015621777

Chickering, A. W., \& Ehrmann, S. C. (1996). Implementing the seven principles: Technology as lever. AAHE Bulletin, 49, 3-6.

Donovan, J. (2020, July 1). The importance of building online learning communities. Colorado State University Blog. https://blog.online.colostate.edu/blog/uncategorized/the-importance-of-buildingonline-learning-communities/

Erickson, A., \& Neset, C. (2014, September 8). Building community and creating relevance in the online classroom. Faculty Focus. https://www.facultyfocus.com/articles/online-education/buildingcommunity-creating-relevance-online-classroom/

Gares, S. L., Kariuki, J. K., \& Rempel, B. P. (2020). Community matters: Student-instructor relationships foster student motivation and engagement in an emergency remote teaching environment. Journal of Chemical Education, 97(9), 3332-3335. https://doi.org/10.1021/acs.jchemed.oco06351

Kaufmann, R., \& Vallade, J. I. (2020). Exploring connections in the online learning environment: Student perceptions of rapport, climate, and loneliness. Interactive Learning Environments, 1-15. https://doi.org/10.1080/10494820.2020.1749670

Kotera, Y., Green, P., Rhodes, C., Williams, A., Chircop, J., Spink, R., Rawson, R., \& Okere, U. (2020). Dealing with isolation using online morning huddles for university lectures during physical distancing by COVID-19: Field notes. International Review of Research in Open and Distributed Learning, 21(4), 238-244.

Muirhead, B. (2007). Integrating creativity into online university classes. Educational Technology and Society, $10(1), 1-13$.

Mullinix, B. B. (2018, June 24-27). Creating community: Promoting choice, choice and connectivity via free apps [Paper presentation]. DLA 2018 Distance Learning Administration Conference, Jekyll Island, GA, United States. https://tinyurl.com/DLA18-Community

O’Malley, S. (2017, July 26). Professors share ideas for building community in online courses. Inside Higher Ed. https://www.insidehighered.com/digital-learning/article/2017/07/26/ideas-building-onlinecommunity

Palloff, R. M., \& Pratt, K. (1999). Building learning communities in cyberspace: Effective strategies for the online classroom. Jossey-Bass.

Rovai, A. P., \& Jordan, H. M. (2004). Blended learning and sense of community: A comparative analysis with traditional and fully online graduate courses. International Review of Research in Open and Distance Learning 5(2). https://doi.org/10.19173/irrodl.v5i2.192

Shea, V. (2004). Netiquette. http://www.albion.com/netiquette/

Stevenson, C. N., \& Bauer, J. C. (Eds.). (2014). Building online communities in higher education institutions: Creating collaborative experience. IGI Global.

Stone, K. (2016, February 3). Building community in online courses. CDLT Research to Practice Blog. http://www.aaace.org/news/272788/Building-Community-in-Online-Courses.htm

Talbert, R. (2015, October 2). How student video presentations can build community in an online course. The Chronicle of Higher Education. https://www.chronicle.com/blogs/wiredcampus/how-student-videopresentations-can-build-community-in-an-online-course/57435 
Trespalacios, J., \& Perkins, R. (2016). Sense of community, perceived learning, and achievement relationships in an online graduate course. Turkish Online Journal of Distance Education, 17(3), 31-49. https://doi.org/10.17718/tojde.12984

Vincenzes, K. A., Drew, M., \& Romero, L. (2015). Residencies in an online doctoral program. Vistas Online, Article 34. https://www.counseling.org/docs/defaultsource/vistas/article_346a5c21f16116603abcacffoooobee5e7.pdf?sfvrsn=f44a412c_8

Wehler, M. (2018, July 11). Five ways to build community in online classrooms. Faculty Focus. https://www.facultyfocus.com/articles/online-education/five-ways-to-build-community-in-onlineclassrooms/

Williams, G. (2011, March 4). Use GoogleDocs for crowd-sourced notes. ProfHacker. https://www.chronicle.com/blogs/profhacker/use-googledocs-for-crowd-sourced-notes/31644

Zhang, X., Peng, L., \& Gong, Y. (2020). The impact of interdependence on behavioral engagement in online communities. Marketing Intelligence and Planning, 38(4), 417-431. https://doi.org/10.1108/MIP05-2019-0285

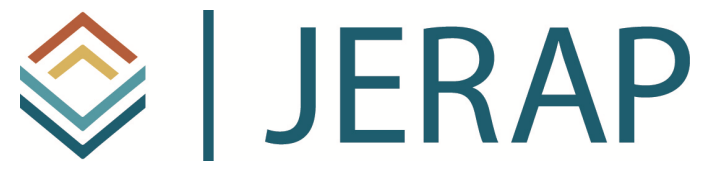

The Journal of Educational Research and Practice is a peerreviewed journal that provides a forum for studies and dialogue about developments and change in the field of education and learning. The journal includes research and related content that examine current relevant educational issues and processes. The aim is to provide readers with knowledge and with strategies to use that knowledge in educational or learning environments. JERAP focuses on education at all levels and in any setting, and includes peer-reviewed research reports, commentaries, book reviews, interviews of prominent individuals, and reports about educational practice. The journal is sponsored by The Richard W. Riley College of Education and Leadership at Walden University, and publication in JERAP is always free to authors and readers. 